\title{
RESEARCH
}

Open Access

\section{Inequalities in the prevalence of diabetes mellitus and its risk factors in Sri Lanka: a lower middle income country}

Ambepitiyawaduge Pubudu De Silva ${ }^{1 *}$ (D, Sudirikku Hennadige Padmal De Silva', Rashan Haniffa ${ }^{2}$, Isurujith Kongala Liyanage ${ }^{3}$, Saroj Jayasinghe ${ }^{4}$, Prasad Katulanda ${ }^{4}$, Chandrika Neelakanthi Wijeratne ${ }^{5}$, Sumedha Wijeratne ${ }^{5}$ and Lalini Chandika Rajapaksa'

\begin{abstract}
Background: Explorations into quantifying the inequalities for diabetes mellitus (DM) and its risk factors are scarce in low and lower middle income countries (LICS/LMICS). The aims of this study were to assess the inequalities of DM and its risk factors in a suburban district of Sri Lanka.

Methods: A sample of 1300 participants, (aged 35-64 years) randomly selected using a stratified multi-stage cluster sampling method, were studied employing a cross sectional descriptive design. The socioeconomic indicators (SEls) of the individual were education level and occupational category, and at the household level, the household income, social status level and area deprivation level. DM was diagnosed if the fasting plasma glucose was $\geq 126$ and a body mass index (BMI) of $>27.5 \mathrm{~kg} / \mathrm{m}^{2}$ was considered high. Asian cut-off values were used for high waist circumference (WC). Validated tools were used to assess the diet and level of physical activity. The slope index of inequality (SII), relative index of inequality (RII) and concentration index (Cl) were used to assess inequalities.

Results: The prevalence of DM and its risk factors (at individual or household level) showed no consistent relationship with the three measures of inequality (SII, RII and CI) of the different indices of socio economic status (education, occupation, household income, social status index or area unsatisfactory basic needs index).

The prevalence of diabetes showed a more consistent pro-rich distribution in females compared to males. Of the risk factors in males and females, the most consistent and significant pro-rich relationship was for high BMI and WC. In males, the significant positive relationship with high BMI for SII ranged from 0.18 to 0.35, and RII from 1.56 to 2 . 25. For high WC, the values were: SII from 0.13 to 0.27 and RII from 1.9 to 3.97. In females the significant positive relationship with high BMI in SII ranged from 0.13 to 0.29 , and RII from 2.3 to 4.98 . For high WC the values were: SII from 028 to 0.4 and RII 1.99 to 2.39 .

Of the other risk factors, inadequate fruit intake showed a consistent significant pro-poor distribution only in males using SII (- 0.25 to -0.36$)$ and in both sexes using Cl. Smoking also showed a pro-poor distribution in males especially using individual measures of socio-economic status (i.e. education and occupation).

(Continued on next page)
\end{abstract}

\footnotetext{
* Correspondence: pubududesilva@ymail.com

'Department of Community Medicine, Faculty of Medicine, University of

Colombo, Colombo, Sri Lanka

Full list of author information is available at the end of the article
}

(c) The Author(s). 2018 Open Access This article is distributed under the terms of the Creative Commons Attribution 4.0 International License (http://creativecommons.org/licenses/by/4.0/), which permits unrestricted use, distribution, and reproduction in any medium, provided you give appropriate credit to the original author(s) and the source, provide a link to the Creative Commons license, and indicate if changes were made. The Creative Commons Public Domain Dedication waiver (http://creativecommons.org/publicdomain/zero/1.0/) applies to the data made available in this article, unless otherwise stated. 
(Continued from previous page)

Conclusions: The results show a variable relationship between socioeconomic status and prevalence of diabetes and its risk factors. The inequalities in the prevalence of diabetes and risk factors vary depending on gender and the measures used. The study suggests that measures to prevent diabetes should focus on targeting specific factors based on sex and socioeconomic status. The priority target areas for interventions should include prevention of obesity (BMI and central obesity) specifically in more affluent females. Males who have a low level of education and in non-skilled occupations should be especially targeted to reduce smoking and increase fruit intake.

Keywords: Inequalities, Diabetes mellitus, Risk factors of diabetes mellitus, Lower middle income country

\section{Background}

Diabetes mellitus (DM) is a major non-communicable disease contributing to mortality, morbidity and other non-communicable diseases. There were approximately 171 million adults with diabetes mellitus worldwide in the year 2000 and this is projected to rise to 366 million by 2030 [1]. The highest percentage of increase (> 100\%) of diabetes mellitus prevalence is observed in low income countries/lower middle income countries while high income countries experience an increase of $54 \%$ [1]. The diabetes burden in low income countries/lower middle income countries is double that of high income countries for all age groups [1]. Among the South Asian region India, Pakistan and Bangladesh are within the top ten countries projected to have the highest numbers of adults with diabetes mellitus for 2000 and 2030 [1].

Although the excess global mortality of diabetes mellitus is reported to be $5.2 \%$ of all deaths it causes significant debilitation with its complications and associations with other non-communicable diseases [2, 3]. Unlike other non-communicable diseases that cause acute mortality, diabetes mellitus may persist for a lengthy period with the complications causing a heavy economic burden to the state [4]. The life expectancy loss due to diabetes mellitus has been estimated to be less than 7.5 years among those with diabetes mellitus compared to their non-diabetes equivalents $[5,6]$. A person with diabetes mellitus lives with the disease, requiring treatment for its control and complications, thereby incurring heavy costs for nations [7]. A person with diabetes mellitus has 2.3 times the medical expenditure of a person without the disease and account for more than 1 in 5 health care dollars in the USA [8]. The economic loss in the African region ranges from $\$ 2144.3$ to $\$ 11,431.6$ per diabetes case per year [9].

Due to its high burden and economic cost it is imperative that diabetes mellitus is prevented. Towards this end community screening for the presence of disease, its complications and risk factors, and life style modification programs in the primary health care setting have been introduced. However the alarming increase in the prevalence of this disease and its complications in low income countries/lower middle income countries demonstrates the failure of primary and secondary prevention measures in these settings $[10,11]$. Although technical and medical solutions such as disease control and medical care within the health sector are important they alone are not sufficient. Improvements in living and working conditions and access to known medical solutions, would lead to dramatic reductions in the inequalities of the disease. Addressing the social determinants of health can yield greater and sustainable returns. Action on social determinants of health empowers people, communities and countries and empowerment is a potent method to change both social structure and conditions. Also action on the social determinants of health will not only improve individual health but also will indicate that society has moved towards meeting human needs and ensuring rights. The advantages of a social determinant of the health approach are: it bridges the artificial distinction between technical and social interventions; it seeks to redress the imbalance between curative and preventive action, individualized and population-based interventions and act on structural conditions in society. Thus a social determinants approach offers a better hope for sustainable and equitable outcomes [12].

The lack of a social determinants approach in the preventive strategies employed may have contributed to the failure [12] of current approaches to tackle DM. In order to develop a social determinants approach it is necessary to assess the inequalities in the distribution of diabetes mellitus and its risk factors.

Most studies on social determinants of health are from high-income countries and they demonstrate health inequalities in the distribution of the disease and risk factors with higher prevalence rates of the disease observed in the poor and marginalized. Studies from the European continent have demonstrated inequalities in the prevalence of DM and its complications due to socioeconomic position with lower socio-economic communities being more affected compared to higher socio-economic groups [13-17]. Many of these studies use the Slope Index of Inequality (SII) and the Relative Index of Inequality (RII). Evidence from lower middle income settings suggests that poverty is associated with higher diabetes incidence and inequality of diabetes care $[18,19]$. Although surveys in South Asia describe higher prevalence of DM associated 
with higher economic status, these studies do not quantify inequality [20-25].

In Sri Lanka the incidence of DM and its risk factors show a steady rise and a positive association with economic status [26-31]. Interestingly all surveys on DM and its risk factors in Sri Lanka do not describe the distribution in the plantation sector. The plantation sector comprises of all plantations which are 20 acres or more in extent and ten or more resident laborers and came into being during the colonial period. It comprises the lowest socioeconomic category and comparatively poor infrastructure. The population distribution in urban, rural and plantation sectors in Sri Lanka are approximately $18.3 \%, 77.3 \%$ and $4.4 \%$ respectively [32]. The depth and severity of poverty are also the highest among estate sector in Sri Lanka as shown by a head count index $32 \%$, poverty gap index $6.2 \%$ and poor households $25.8 \%$. Individuals living in estate communities experience a variety of economic and social constraints, including short falls in access to productive assets like land and water, gap in physical infrastructures like power, transport and communications, imperfectly functioning product and input markets, inadequate technology and weak institutional arrangements. The health inequalities are more marked in the plantation sector with basic health indictors such as maternal mortality rate and infant mortality rates being higher compared to others [32]. We have studied a representative sample from all three sectors and reported the social gradients observed in the prevalence of diabetes mellitus in Sri Lanka [33]. This report examined social gradient of the prevalence of diabetes and its risk factors across different socio-economic strata using chi square test for trend [33]. This method is best suited in situations where there is a linear ascending or descending trend or gradient in a health outcome, across socio-economic status. Therefore, in the present analysis we explore inequalities in diabetes prevalence and its risk factors using other indices the SII, the RII and the concentration index. We compare these across individual, household and area level socioeconomic indices and its variability for diabetes mellitus and its selected risk factors.

\section{Methods}

A detailed description of the study methods has been published in 2012 [33, 34]. A cross sectional design with stratified multistage cluster sampling was used to randomly select 1300 adults between the ages of 35 to 64 years from the Kalutara district, which comprises of urban, rural and plantation sectors. A sample size of 1300 was reached calculated based on $16 \%$ prevalence of $\mathrm{DM}$, with a margin of error at $3 \%, \alpha$ error at $5 \%$, dropout rate of $10 \%$ and cluster effect of 2 . In order to produce a wider scatter of the sample the cluster size was limited to 20 as people of similar socioeconomic status tend to cluster together. The level of stratifications was at the urban, rural and plantation sectors with the Grama Niladari Division (GND) (GND the lowest village level administrative division in Sri Lanka) being the primary sampling unit. GNDs were randomly selected, probability proportionate to the size of its population of 35 to 64 years age group. Within each GND 20 households were randomly selected using the electoral registry and a single eligible individual was randomly selected from each selected household. Information was gathered using validated questionnaires administered by trained data collectors. Anthropometric measurements and laboratory investigations for fasting plasma glucose were also conducted.

We used the following definitions for the categorization of study participants; participants were categorized as suffering from DM if they were on insulin or hypoglycaemics within the past four weeks or if they had a fasting plasma glucose of $\geq 126 \mathrm{mg} / \mathrm{dl}$ [35]; they were categorized as having an impaired glucose tolerance if they had fasting plasma glucose of $\geq 100 \mathrm{mg} / \mathrm{dl}$ and $<126 \mathrm{mg} / \mathrm{dl}$ [35]; a body mass index of $>27.5 \mathrm{~kg} / \mathrm{m}^{2}$ was considered high while waist circumferences of $\geq 90 \mathrm{~cm}$ and $\geq 80 \mathrm{~cm}$ were regarded as high for men and women respectively [36-38]. A presence of a family history of DM was deemed when parents or siblings were known to have diabetes mellitus. A culturally adapted version of the International Physical Activity Questionnaire validated for Sri Lanka [39] was used to assess the level of physical activity. It assesses vigorous, moderate and mild physical activities carried out during the past week and classifies the subjects into insufficiently active, sufficiently active and highly active categories. The quality of diet was assessed with a tool developed and validated for Sri Lanka [39]. The tool grouped fruit and sugar intake in the diet, based on a scoring system described by Arembepola [39]. Those who consumed at least one glass of alcohol during the past fortnight were classified as alcohol users while those who smoked at least once during the past fortnight were classified as smokers.

The highest level of education attained was recorded. Occupation was classified as mentioned by the Registrar General in Britain and adapted to the local setting [40]. Monthly household income was obtained in local currency (Sri Lankan Rupees). Social status index (SSI) was assessed as described by De Silva [40] and the Unsatisfactory Basic Needs Index (UBNI) as described by Satharasinghe [41].

Analysis was conducted with STATA 13. All results presented were weighted and standardized for age and sex of the Sri Lankan population.

The SII, RII and concentration index were employed to measure health inequality [42-44]. SII and RII are regression-based indexes used to illustrate the magnitude 
of socioeconomic position as a source of inequalities in health. The approach involves calculating the mean health status of each socioeconomic group and then ranking classes by their socioeconomic status (not by their health). SII and RII reflect the socioeconomic dimension to inequalities in health. SII measures the absolute effect while RII measures relative inequality. We calculated SII and RII as described by Schneider et al. [44].

SII (rate difference) is slope of the regression line estimated by the weighted least square method and represents the change in measured outcome event when the position of the socioeconomic status changes by one unit.

The approach for SII is creating a weighted sample of the whole population which is ranked from the most disadvantaged subgroup (at rank 0) to the most advantaged (at rank 1) according to, selected socioeconomic indicator (eg. level of education or income). The population of each socioeconomic category is considered in terms of its range in the cumulative population distribution, and the midpoint of this range. The health indicator of interest is regressed against this midpoint value for selected socioeconomic indicator wealth or education subgroups using an appropriate model. The predicted values of the health indicator are calculated for the two extremes (rank 1 and rank 0). The difference between the predicted values at rank 1 and rank 0 (covering the entire distribution) generates the slope index of inequality value. The slope index of inequality (SII) is then defined as the slope of the regression line showing the relationship between a class's health status and its relative rank $(R$, in the socioeconomic distribution. It can be interpreted as the absolute effect on health of moving from the lowest socioeconomic group through to the highest.

RII (rate ratios) can be estimated in two ways: one way is to divide the SII by the mean level of population health or by the frequency of the health problem in the population, the other way is to divide the predicted value of the regression at the highest point (range $=1$ ) by the predicted value of the regression at the lowest point (range $=0$ ), The second method for the RII is calculated by $\log$-linear or logistic regression after the logarithmic $r$ logit transformation of the dependent variable.

Because SII is an absolute measure, it is sensitive to changes in the mean level of population health or changes in the frequency of the health problem being studied. If the mean level of health increases in the same proportion in all the socioeconomic categories, the SII will increase, whereas the relative differences remain constant.

The concentration index is a bivariate measure, which uses the distribution of a health variable and a variable describing the socioeconomic standards against which the distribution is to be assessed [45]. This accounts for both the strength of the association and the magnitude of differences between health variable and relative rank in the socioeconomic distribution. This index is based on the "concentration curve" which plots the cumulative percentage of the health variable (y axis) against the cumulative percentage of the population, ranked by socioeconomic level, beginning with the poorest, and ending with the richest ( $x$-axis). The concentration index is defined as twice the area between the concentration curve and the line of equality (the 45degree line). The index lies between -1 and 1 . When there is no socioeconomic-related inequality, the concentration index is zero. The concentration index can be computed for good health as well as ill health. The index has a negative value when the curve lies above the line of equality, indicating disproportionate concentration of the health variable among the poor, and a positive value when it lies below the line of equality.

Ethics approval was received from the Ethics Review Committee of Faculty of Medicine, University of Colombo (Reference Number: EC/08/119). Written informed consent was obtained from all study participants.

\section{Results}

The age and sex adjusted diabetes mellitus prevalence was $14.7 \%$ from a representative sample in Sri Lanka and the distribution of the study sample and its representativeness has been described previously [33]. The socio-demography of the study population by fasting glucose levels is described in Table 1 [33]. Using the same database we calculated the SII, RII and concentration index for diabetes and its risk factors on individual education, individual occupation, household level income, household level SSI, and UBNI, which is an area level deprivation index.

Inequalities in the prevalence of diabetes varied across gender and depending on the measures used. Using SII (Table 2) showed a significant and consistent positive relationship between prevalence of diabetes in females and different measures of inequalities at individual, household and area-wise deprivation (i.e. increases in prevalence with higher income or higher social status). At the individual level the SII of occupations were significant, though in opposite directions both sexes (i.e. higher prevalence seen with 'lower' strata of occupations). In males individual level of education and household income showed a prorich distribution for prevalence of diabetes.

Risk factors for diabetes (high BMI, and high waist circumference) were significant at the household and individual levels for both sexes across several measures of socio-economic status: education, income, social status, and area unsatisfactory basic needs index. A negative relationship between most measures of socioeconomic status (education, income SSI and UBNI) and fruit intake was observed in males. 
Table 1 Socioeconomic determinants of fasting glucose levels among adults in Kalutara, Sri Lanka

\begin{tabular}{|c|c|c|c|c|c|c|c|}
\hline \multirow[t]{3}{*}{ Characteristic } & \multicolumn{6}{|c|}{ Glucose tolerance $(n=1234)$} & \multirow[t]{3}{*}{$p$} \\
\hline & \multicolumn{2}{|c|}{ Normal $(n=832)$} & \multicolumn{2}{|c|}{ IFG $(n=200)$} & \multicolumn{2}{|c|}{$\mathrm{DM}(n=202)$} & \\
\hline & Number & Percent & Number & Percent & Number & Percent & \\
\hline \multicolumn{8}{|l|}{ Sex } \\
\hline Male & 437 & $75.7 \%$ & 93 & $10.2 \%$ & 98 & $14.1 \%$ & 0.236 \\
\hline Female & 395 & $66.6 \%$ & 107 & $18.2 \%$ & 104 & $15.2 \%$ & \\
\hline Age category & & & & & & & $<0.001^{\mathrm{a}}$ \\
\hline 35 to 39 Years & 152 & $84.6 \%$ & 23 & $10.6 \%$ & 11 & $4.8 \%$ & \\
\hline 40 to 44 Years & 164 & $74.7 \%$ & 28 & $13.0 \%$ & 29 & $12.3 \%$ & \\
\hline 45 to 49 Years & 142 & $71.4 \%$ & 36 & $12.6 \%$ & 39 & $16.0 \%$ & \\
\hline 50 to 54 Years & 124 & $62.9 \%$ & 38 & $18.6 \%$ & 40 & $18.6 \%$ & \\
\hline 55 to 59 Years & 136 & $58.0 \%$ & 47 & $18.5 \%$ & 43 & $23.4 \%$ & \\
\hline 60 to 64 Years & 114 & $66.9 \%$ & 28 & $14.4 \%$ & 40 & $18.7 \%$ & \\
\hline \multicolumn{8}{|l|}{ Ethnicity } \\
\hline Sinhalese & 554 & $71.2 \%$ & 130 & $14.4 \%$ & 156 & $14.4 \%$ & \\
\hline Tamil & 208 & $60.6 \%$ & 50 & $10.4 \%$ & 23 & $29.0 \%$ & \\
\hline Muslim & 69 & $68.5 \%$ & 19 & $11.6 \%$ & 22 & $20.0 \%$ & 0.003 \\
\hline Other & 01 & $91.5 \%$ & 01 & $3.3 \%$ & 01 & $05.2 \%$ & \\
\hline \multicolumn{8}{|l|}{ Sector } \\
\hline Urban & 224 & $58.6 \%$ & 68 & $17.8 \%$ & 90 & $23.6 \%$ & \\
\hline Rural & 397 & $69.9 \%$ & 83 & $14.6 \%$ & 88 & $15.5 \%$ & $0.001^{\mathrm{a}}$ \\
\hline Plantation & 211 & $74.3 \%$ & 49 & $17.3 \%$ & 24 & $08.5 \%$ & \\
\hline \multicolumn{8}{|l|}{ Education category } \\
\hline No schooling & 35 & $73.8 \%$ & 07 & $9.8 \%$ & 06 & $16.4 \%$ & \\
\hline Grade 5 or below & 199 & $76.5 \%$ & 53 & $10.9 \%$ & 31 & $12.6 \%$ & \\
\hline Grade 6 to 10 & 274 & $70.5 \%$ & 56 & $13.4 \%$ & 78 & $16.1 \%$ & $0.019^{a}$ \\
\hline O/L to Grade 12 & 190 & $72.9 \%$ & 49 & $15.3 \%$ & 45 & $11.8 \%$ & \\
\hline AL and above & 91 & $66.9 \%$ & 25 & $15.8 \%$ & 31 & $17.3 \%$ & \\
\hline \multicolumn{8}{|l|}{ Occupation category } \\
\hline Professional & 07 & $97.5 \%$ & 02 & $1.0 \%$ & 03 & $1.4 \%$ & \\
\hline Technical \& clerical & 38 & $72.3 \%$ & 11 & $15.3 \%$ & 12 & $12.4 \%$ & \\
\hline Vendors \& sellers & 82 & $60.0 \%$ & 23 & $14.3 \%$ & 31 & $25.6 \%$ & 0.175 \\
\hline Skilled manual workers & 160 & $84.8 \%$ & 24 & $7.9 \%$ & 21 & $7.2 \%$ & \\
\hline Unskilled manual workers & 181 & $74.8 \%$ & 36 & $14.3 \%$ & 23 & $10.8 \%$ & \\
\hline Retired & 35 & $60.2 \%$ & 15 & $19.7 \%$ & 14 & $20.1 \%$ & \\
\hline Unemployed & 40 & $70.6 \%$ & 8 & $6.5 \%$ & 11 & $22.9 \%$ & \\
\hline Housewife & 257 & $65.5 \%$ & 76 & $18.1 \%$ & 82 & $16.4 \%$ & \\
\hline \multicolumn{8}{|l|}{ Income Category (per month) } \\
\hline$<10,000$ & 293 & $73.2 \%$ & 66 & $12.4 \%$ & 53 & $14.3 \%$ & \\
\hline 10,000 to 30,000 & 440 & $70.3 \%$ & 107 & $14.5 \%$ & 113 & $15.1 \%$ & $0.005^{\mathrm{a}}$ \\
\hline$>30,000$ & 74 & $64.7 \%$ & 23 & $19.2 \%$ & 35 & $16.1 \%$ & \\
\hline \multicolumn{8}{|l|}{ Social status index } \\
\hline 1st quintile & 158 & $66.3 \%$ & 38 & $16.3 \%$ & 47 & $17.4 \%$ & \\
\hline 2nd quintile & 153 & $71.1 \%$ & 39 & $14.5 \%$ & 51 & $14.5 \%$ & \\
\hline
\end{tabular}


Table 1 Socioeconomic determinants of fasting glucose levels among adults in Kalutara, Sri Lanka (Continued)

\begin{tabular}{|c|c|c|c|c|c|c|c|}
\hline \multirow[t]{3}{*}{ Characteristic } & \multicolumn{6}{|c|}{ Glucose tolerance $(n=1234)$} & \multirow[t]{3}{*}{$p$} \\
\hline & \multicolumn{2}{|c|}{ Normal $(n=832)$} & \multicolumn{2}{|c|}{ IFG $(n=200)$} & \multicolumn{2}{|c|}{$\mathrm{DM}(n=202)$} & \\
\hline & Number & Percent & Number & Percent & Number & Percent & \\
\hline 3rd quintile & 158 & $73.2 \%$ & 39 & $12.0 \%$ & 45 & $14.7 \%$ & $0.006^{\mathrm{a}}$ \\
\hline 4th quintile & 163 & $71.7 \%$ & 38 & $14.7 \%$ & 42 & $13.6 \%$ & \\
\hline 5th quintile & 182 & $76.1 \%$ & 43 & $16.9 \%$ & 17 & $7.0 \%$ & \\
\hline \multicolumn{8}{|l|}{ UBNI } \\
\hline 1 & 80 & $91.0 \%$ & 07 & $4.7 \%$ & 08 & $4.3 \%$ & \\
\hline 2 & 119 & $93.6 \%$ & 34 & $1.4 \%$ & 13 & $5.0 \%$ & \\
\hline 3 & 176 & $70.8 \%$ & 44 & $16.9 \%$ & 28 & $12.3 \%$ & $<0.001^{\mathrm{a}}$ \\
\hline 4 & 214 & $71.6 \%$ & 46 & $13.6 \%$ & 64 & $14.7 \%$ & \\
\hline 5 & 243 & $63.3 \%$ & 69 & $16.0 \%$ & 89 & $20.7 \%$ & \\
\hline
\end{tabular}

${ }^{a}$ chi square test for trend was used. IFG: Impaired Glucose Tolerance, DM: Diabetes Mellitus, IFG: Impaired Fasting Glucose; UBNI: Unsatisfactory Basic Needs Index

Table 3 shows the comparison of the RII for diabetes mellitus and its risk factors among males and females by different measures of socio economic statuses. There were significant inequalities for prevalence of diabetes only in females at individual education level, household levels (i.e. household income and social status) and area unsatisfactory basic needs index. Here too there was significant inequalities for risk factors (high body mass index and high waist circumference) across most of the socioeconomic measures for both sexes (individual education levels, household income, social status index, area unsatisfactory basic needs index).

Table 4 describes the comparison of the concentration indexes for diabetes mellitus and its risk factors by different measures of socio economic status. Only males were included for the sections on smoking and alcohol because female consumption rates are almost nil. The concentration index is positive for prevalence of diabetes mellitus across household income for both sexes.

Insufficient physical activity, alcohol intake and sugar intake did not show a consistent relationship across most of the socio-economic status of males and females. Too much emphasis cannot be attributed to family history of diabetes because it is not a modifiable risk factor and relatively well analyzed in the existing literature.

\section{Discussion}

The results show the presence of a variable relationship between socioeconomic status and prevalence of diabetes and its risk factors, depending on the measures of inequalities used. However, there is a relatively consistent relationship observed where prevalence of diabetes is higher in those with better individual levels of education and occupation, and higher household incomes. The prevalence of risk factors (high BMI, and high WC) for both sexes is also significantly higher in those with better individual education and higher socio-economic status (i.e. using household income, social status index and area unsatisfactory basic needs index - SII and RII). Inadequate fruit intake and smoking (among males) demonstrated a pro-poor relationship indicating adverse dietary habits in these groups.

Early literature from high income countries reported a pattern where the affluent were at high risk of diabetes [46] In comparison, more recent literature from these countries report higher rates of diabetes mellitus and its risk factors in the poorer population groups [16, 47-52].

This suggests that during economic transitions adverse health behaviors are initially encountered in the higher socioeconomic sector and are later transmitted to the lower socioeconomic groups [53]. It may also be that higher socioeconomic categories modify their risky behavior early while lower socioeconomic categories persist with the adverse health behaviors during the course of a country's economic development [53]. It is possible that similar factors are operating in Sri Lanka. The pro rich pattern of diabetes and its risk factors and the relatively small magnitude of the slope index seen in the present study may suggest that the country is in an economic transitional stage [45].

The inequality also seemed to vary depending on the sex of the individual. The inequalities for the prevalence of diabetes mellitus were more marked for females possibly due to the gender differences in health behavior, as shown by the correspondingly reduced physical activity and inadequate fruit intake in females. Similar observations were made for females in Europe on the prevalence of diabetes mellitus and obesity [16, 48, 54], where these were attributed to the corresponding gender differences in health behaviors; it is possible these differences are exaggerated in South Asian or lower middle income settings. Females also had a higher SII and RII for diabetes mellitus and its risk factors in relation to household level SSI compared to males. This may possibly be due to the 
Table 2 Comparison of the slope index of inequality for diabetes mellitus and its risk factors among males and females by different measures of socio economic statuses

\begin{tabular}{|c|c|c|c|c|c|}
\hline \multirow[t]{2}{*}{ Morbidity / risk factor } & \multicolumn{2}{|l|}{ Individual } & \multicolumn{2}{|l|}{ Household } & \multirow{2}{*}{$\begin{array}{l}\text { Area } \\
\text { Unsatisfactory Basic } \\
\text { Needs Index }(95 \% \mathrm{Cl})\end{array}$} \\
\hline & Education (95\%Cl) & Occupation $(95 \% \mathrm{Cl})$ & Income $(95 \% \mathrm{Cl})$ & Social Status Index $(95 \% \mathrm{Cl})$ & \\
\hline \multicolumn{6}{|l|}{ Male } \\
\hline $\begin{array}{l}\text { Prevalence of diabetes } \\
\text { mellitus }\end{array}$ & $0.12(0.01-0.22)^{*}$ & $-0.15(-0.2--0.01)^{*}$ & $0.16(0.05-0.27)^{*}$ & $0.02(-0.08-0.11)$ & $0.08(-0.01-0.17)$ \\
\hline $\begin{array}{l}\text { Prevalence of impaired } \\
\text { glucose tolerance }\end{array}$ & $0.1(-0.01-0.21)$ & $-0.2(-0.38--0.02)^{*}$ & $0.05(-0.08-0.17)$ & $-0.02(-0.13-0.09)$ & $0.07(-0.03-0.18)$ \\
\hline High body mass index & $0.35(0.21-0.49)^{*}$ & $-0.31(-0.5--0.13)^{*}$ & $0.25(0.11-0.4)^{*}$ & $0.18(0.05-0.31)^{*}$ & $0.27(0.14-0.4)^{*}$ \\
\hline High waist circumference & $0.27(0.15-0.38)^{*}$ & $-0.34(-0.5--0.18)^{*}$ & $0.28(0.16-0.39)^{*}$ & $0.13(0.01-0.25)^{*}$ & $0.23(0.12-0.34)^{*}$ \\
\hline $\begin{array}{l}\text { Family history of diabetes } \\
\text { mellitus }\end{array}$ & $0.17(0.04-0.31)^{*}$ & $0.06(-0.15-0.27)$ & $0.08(-0.06-0.21)$ & $0.13(0.02-0.25)^{*}$ & $0.27(0.15-0.39)^{*}$ \\
\hline $\begin{array}{l}\text { Insufficient physical } \\
\text { activity }\end{array}$ & $0.02(-0.11-0.16)$ & $-0.20(-0.4-0.001)$ & $0.09(-0.05-0.23)$ & $0.001(-0.12-0.12)$ & $0.36(-0.08-0.16)$ \\
\hline Inadequate fruit intake & $-0.36(-0.49--0.23)^{*}$ & $0.4(0.18-0.61)^{*}$ & $-0.33(-0.47--0.18)^{*}$ & $-0.25(-0.37--0.13)^{*}$ & $-0.32(-0.44--0.21)^{*}$ \\
\hline Inappropriate sugar intake & $0.01(-0.12-0.14)$ & $-0.1(-0.31-0.1)$ & $0.08(-0.07-0.022)$ & $0.02(-0.11-0.14)$ & $0.03(-0.1-0.15)$ \\
\hline Smoking & $-0.18(-0.32--0.03)^{*}$ & $0.34(0.11-0.56)^{*}$ & $-0.17(-0.33--0.12)^{*}$ & $-0.12(-0.25-0.01)$ & $0.01(-0.12-0.15)$ \\
\hline Alcohol consumption & $0.01(-0.13-0.16)$ & $0.08(-0.14-0.29)$ & $0.05(-0.1-0.2)$ & $-0.11(-0.23-0.1)$ & $-0.22(-0.34--0.1)^{*}$ \\
\hline \multicolumn{6}{|l|}{ Female } \\
\hline $\begin{array}{l}\text { Prevalence of diabetes } \\
\text { mellitus }\end{array}$ & $0.14(0.2-0.25)^{*}$ & $-0.34(-0.61--0.07)^{*}$ & $0.13(0.02-0.24)^{*}$ & $0.21(0.11-0.31)^{*}$ & $0.29(0.2-0.38)^{*}$ \\
\hline $\begin{array}{l}\text { Prevalence of impaired } \\
\text { glucose tolerance }\end{array}$ & $0.01(-0.12-0.15)$ & $0.15(-0.13-0.43)$ & $0.07(-0.07-0.21)$ & $0.04(-0.07-0.15)$ & $0.05(-0.06-0.16)$ \\
\hline High body mass index & $0.37(0.23-0.52)^{*}$ & $-0.54(-0.8-0.28)$ & $0.23(0.08-0.38)^{*}$ & $0.41(0.29-0.52)^{*}$ & $0.5(0.38-0.62)^{*}$ \\
\hline High waist circumference & $0.37(0.22-0.51)^{*}$ & $-0.56(-0.81--0.31)^{*}$ & $0.28(0.13-0.43)^{*}$ & $0.35(0.23-0.47)^{*}$ & $0.4(0.28-0.53)^{*}$ \\
\hline $\begin{array}{l}\text { Family history of diabetes } \\
\text { mellitus }\end{array}$ & $0.15(0.02-0.28)^{*}$ & $-0.43(-0.73--0.12)^{*}$ & $0.09(-0.04-0.22)$ & $0.17(0.07-0.28)^{*}$ & $0.23(0.12-0.33)^{*}$ \\
\hline $\begin{array}{l}\text { Insufficient physical } \\
\text { activity }\end{array}$ & $-0.03(-0.17-0.11)$ & $0.22(-0.06-0.49)$ & $-0.02(-0.15-0.11)$ & $-0.13(-0.24--0.03)^{*}$ & $-0.1(-0.21-0.02)$ \\
\hline Inadequate fruit intake & $-0.14(-0.29-0.01)$ & $0.28(-01-0.66)$ & $-0.19(-0.34--0.04)^{*}$ & $-0.23(-0.34--0.12)$ & $-0.2(-0.33--0.07)^{*}$ \\
\hline $\begin{array}{l}\text { Inappropriate sugar } \\
\text { intake }\end{array}$ & $0.05(-0.09-0.19)$ & $0.22(-0.13-0.57)$ & $0.01(-0.13-0.16)$ & $0.09(-0.03-0.21)$ & $0.57(0.34-0.81)^{*}$ \\
\hline
\end{tabular}

females' enhanced role in social networking compared to males in this study setting, as it was included for the assessment of SSI.

The study suggests that measures to prevent diabetes should target specific factors based on sex and socio economic status rather than implementing interventions as blanket coverage and helps identify such areas and groups.

The weakest relationship between prevalence of diabetes and its risk factors in relation to socioeconomic status was observed with the concentration index. The inequality measures are known to be influenced by extreme wealth/poverty and less extreme incomes $[55,56]$. Therefore the performance of these inequity measures in LIC/LMICs requires further investigation.

Our study is unique as it assesses the inequalities of diabetes mellitus and its risk factors in a district of a lower middle income country with free healthcare for all at the point of delivery. However, we did not explore possible interactions between each of these socioeconomic indicators. Therefore we cannot speculate on the effect of a change in the inequality of a single socioeconomic indicator, on the distribution of diabetes mellitus and its risk factors. Further the study dichotomized alcohol consumption and smoking (i.e. alcohol users or smokers as one or more glasses of alcohol or smoked at least once during the past fortnight). This fails to capture the extent of smoking or alcohol across socioeconomic groups. Measuring prevalence alone may not fully represent inequalities in the impact of the studied health risks; the health impact of the variable level of risk by each risk factor may need to be explored. As patterns of distribution of risk factors over time are not seen in this study, further longitudinal studies are needed to track these changes and to understand the 
Table 3 Comparison of the relative index of inequality for diabetes mellitus and its risk factors among males and females by different measures of socio economic statuses

\begin{tabular}{|c|c|c|c|c|c|}
\hline \multirow[t]{2}{*}{ Morbidity / risk factor } & \multicolumn{2}{|l|}{ Individual } & \multicolumn{2}{|l|}{ Household } & \multirow{2}{*}{$\begin{array}{l}\text { Area } \\
\text { Unsatisfactory Basic } \\
\text { Needs Index }(95 \% \mathrm{Cl})\end{array}$} \\
\hline & Education (95\%Cl) & Occupation (95\%Cl) & Income $(95 \% \mathrm{Cl})$ & Social status Index (95\%Cl) & \\
\hline \multicolumn{6}{|l|}{ Male } \\
\hline Prevalence of diabetes mellitus & $1.85(0.97-3.52)$ & $0.39(0.19-0.81)$ & $2.5(1.24-5.01)^{*}$ & $1.24(0.69-2.21)$ & $1.79(0.99-3.26)$ \\
\hline $\begin{array}{l}\text { Prevalence of impaired glucose } \\
\text { tolerance }\end{array}$ & $1.87(0.99-3.5)$ & $0.35(0.16-0.76)$ & $1.28(0.62-2.65)$ & $0.88(0.47-1.64)$ & $1.4(0.77-2.57)$ \\
\hline High body mass index & $2.25(1.64-3.1)^{*}$ & $0.55(0.39-0.78)$ & $1.89(1.30-2.74)^{*}$ & $1.56(1.13-2.14)^{*}$ & $2.04(1.46-2.85)^{*}$ \\
\hline High waist circumference & $3.31(2-5.47)^{*}$ & $0.35(0.22-0.57)$ & $3.97(2.20-7.17)^{*}$ & $1.9(1.15-3.16)^{*}$ & $3.21(1.91-5.39)^{*}$ \\
\hline Family history of diabetes mellitus & $1.88(1.15-3.11)^{*}$ & $1.12(0.52-2.39)$ & $1.39(0.75-2.58)$ & $1.52(0.96-2.4)$ & $3.37(1.93-5.88)^{*}$ \\
\hline Insufficient physical activity & $1.08(0.70-1.67)$ & $0.60(0.36-1.01)$ & $1.34(0.84-2.12)$ & $1.0(0.67-1.5)$ & $1.13(0.76-1.69)$ \\
\hline Inadequate fruit intake & $0.57(0.46-0.70)$ & $2.23(1.4-3.56)^{*}$ & $0.61(0.5-0.76)$ & $0.68(0.57-0.82)$ & $0.62(0.52-0.74)$ \\
\hline Inappropriate sugar intake & $0.99(0.67-1.47)$ & $0.76(0.43-1.36)$ & $1.31(0.85-2.03)$ & $1.01(0.69-1.48)$ & $1.05(0.74-1.48)$ \\
\hline Smoking ${ }^{a}$ & $0.65(0.45-0.94)$ & $2.63(1.21-5.7)^{*}$ & $0.68(0.47-0.98)$ & $0.76(0.55-1.04)$ & $1.04(0.76-1.41)$ \\
\hline Alcohol consumption ${ }^{a}$ & $1.02(0.81-1.27)$ & $1.14(0.8-1.64)$ & $1.08(0.86-1.35)$ & $0.84(0.7-1.02)$ & $0.73(0.62-0.87)$ \\
\hline \multicolumn{6}{|l|}{ Female } \\
\hline Prevalence of diabetes mellitus & $2.3(1.22-4.34)^{*}$ & $0.13(0.04-0.41)$ & $2.34(1.24-4.43)^{*}$ & $2.37(1.43-3.94)^{*}$ & $4.98(2.71-9.15)^{*}$ \\
\hline $\begin{array}{l}\text { Prevalence of impaired glucose } \\
\text { tolerance }\end{array}$ & $1.03(0.53-1.97)$ & $2.25(0.23-22.5)$ & $1.55(0.82-2.92)$ & $1.19(0.72-1.95)$ & $1.29(0.77-2.16)$ \\
\hline High body mass index & $1.9(1.46-2.47)^{*}$ & $0.38(0.23-0.61)$ & $1.61(1.19-2.17)^{*}$ & $2.05(1.66-2.55)^{*}$ & $2.61(2.01-3.38)^{*}$ \\
\hline High waist circumference & $2.04(1.51-2.75)^{*}$ & $0.32(0.19-0.54)$ & $1.99(1.42-2.79)^{*}$ & $2.02(1.57-2.62)^{*}$ & $2.39(1.79-3.19)^{*}$ \\
\hline Family history of diabetes mellitus & $1.85(1-3.42)$ & $0.13(0.03-0.51)$ & $1.71(0.86-3.40)$ & $2.09(1.25-3.5)^{*}$ & $3.34(1.73-6.46)^{*}$ \\
\hline Insufficient physical activity & $0.86(0.53-1.4)$ & $2.65(0.53-13.18)$ & $0.87(0.53-1.43)$ & $0.57(0.38-0.85)^{*}$ & $0.69(0.47-1.03)$ \\
\hline Inadequate fruit intake & $0.78(0.6-1.01)$ & $1.72(0.77-3.84)$ & $0.72(056-0.94)$ & $0.67(0.55-0.81)$ & $0.71(0.57-0.88)$ \\
\hline Inappropriate sugar intake & $1.14(0.75-1.72)$ & $2.07(0.61-7.05)$ & $1.07(0.7-1.62)$ & $1.32(0.94-1.86)$ & $1.39(0.98-1.96)$ \\
\hline
\end{tabular}

${ }^{*} p<0.05$

Table 4 Comparison of the concentration indexes for diabetes mellitus and its risk factors by different measures of socio economic statuses

\begin{tabular}{|c|c|c|c|c|c|}
\hline \multirow[t]{2}{*}{ Morbidity / risk factor } & \multicolumn{2}{|l|}{ Individual } & \multicolumn{2}{|l|}{ Household } & \multirow{2}{*}{$\begin{array}{l}\text { Area } \\
\text { Unsatisfactory Basic } \\
\text { Needs Index }(95 \% \mathrm{Cl})\end{array}$} \\
\hline & Education $(95 \% \mathrm{Cl})$ & Occupation $(95 \% \mathrm{Cl})$ & Income $(95 \% \mathrm{Cl})$ & Social status Index $(95 \% \mathrm{Cl})$ & \\
\hline $\begin{array}{l}\text { Prevalence of diabetes } \\
\text { mellitus }\end{array}$ & $0.01(-0.1-0.11)$ & $0.12(-0.01-0.25)$ & $0.03(-0.07-0.13)$ & $0.05(-0.05-0.16)$ & $0.17(0.07-0.26)^{*}$ \\
\hline $\begin{array}{l}\text { Prevalence of impaired } \\
\text { glucose tolerance }\end{array}$ & $0.09(-0.03-0.21)$ & $0.07(-0.09-0.24)$ & $0.09(-0.03-0.21)$ & $0.07(-0.05-0.19)$ & $0.12(0.1-0.24)^{*}$ \\
\hline High body mass index & $0.23(0.08-0.37)^{*}$ & $0.2(-0.01-0.4)$ & $0.01(-0.13-0.16)$ & $0.11(-0.03-0.25)$ & $0.19(0.05-0.34)^{*}$ \\
\hline High waist circumference & $0.14(0.01-0.28)^{*}$ & $0.22(0.05-0.39) *$ & $0.03(-0.11-0.16)$ & $0.12(-0.02-0.26)$ & $0.23(0.1-0.37)^{*}$ \\
\hline $\begin{array}{l}\text { Family history of diabetes } \\
\text { mellitus }\end{array}$ & $0.06(-0.07-0.18)$ & $-0.001(-0.18-0.18)$ & $0.05(-0.07-0.17)$ & $0.06(-0.05-0.16)$ & $0.12(0.01-0.23)^{*}$ \\
\hline Insufficient physical activity & $0.11(-0.02-0.23)$ & $-0.18(-0.36--0.002)^{*}$ & $0.02(-0.12-0.15)$ & $0.01(-0.12-0.14)$ & $-0.15(-0.27--0.02)^{*}$ \\
\hline Inadequate fruit intake & $-0.14(-0.28--0.003)^{*}$ & $-0.14(-0.33-0.04)$ & $-0.29(-0.43--0.15)^{*}$ & $-0.41(-0.54--0.28)^{*}$ & $-0.37(-0.5--0.24)^{*}$ \\
\hline Inappropriate sugar intake & $0.20(0.07-0.34)^{*}$ & $0.13(-0.07-0.33)$ & $0.28(0.14-0.42)^{*}$ & $0.33(0.2-0.46)^{*}$ & $0.46(0.33-0.58)^{*}$ \\
\hline Smoking ${ }^{a}$ & $-0.12(-0.35-0.11)$ & $-0.31(-0.56--0.07)^{*}$ & $-0.04(-0.27-0.18)$ & $-0.06(-0.29-0.16)$ & $0.16(-0.07-0.39)$ \\
\hline Alcohol consumption ${ }^{a}$ & $-0.01(-0.21-0.19)$ & $-0.07(-0.28-0.15)$ & $0.01(-0.19-0.21)$ & $0.21(0.001-0.42)^{*}$ & $0.19(-0.02-0.39)$ \\
\hline
\end{tabular}


drivers of these trends. Other diabetes associated risk factors and diseases such as lipid levels and hypertension were not included in the present study, but may show inequalities in their distribution. Future studies may include a broader range of risk factors and non-communicable diseases to provide a more comprehensive distribution of risk profiles across different socioeconomic groups.

This study points to the importance of looking at multiple socioeconomic indicators when examining disparities and implies a specificity of mechanisms that link health inequality to socioeconomic indicators.

\section{Conclusion}

The results show a variable relationship between socioeconomic status and prevalence of diabetes and its risk factors. The inequalities in the prevalence of diabetes and risk factors vary depending on gender and the measure of inequality used. The weakest relationship between prevalence of diabetes and its risk factors in relation to socioeconomic status was observed with the concentration index.

The observations together with the trajectories of prevalence in other countries suggest that Sri Lanka is in a period of economic transition, and that poorer groups may develop relatively higher rates of diabetes, obesity and risk factors in the future.

The study suggests that measures to prevent diabetes should focus on targeting specific factors based on sex and socio economic status. The priority target areas for interventions should include prevention of obesity (BMI and central obesity) specifically in more affluent females. Males who have a low level of education and in nonskilled occupations should be especially targeted to reduce smoking and increase fruit intake.

\section{Abbreviations}

DM: Diabetes Mellitus; RII: Relative Index of Inequality; SII: Slope Index of Inequality; SSI: Social Status Index; UBNI: Unsatisfactory Basic Needs Index

\footnotetext{
Acknowledgements

The authors are thankful to the staff of the National Institute of Health Sciences, Kalutara and all Primary Healthcare Staff of Kalutara Regional Director of Health Services for the immense support rendered.

The authors are also grateful for the National Health Research Council of Ministry of Health, Sri Lanka for partially funding this study.

The authors acknowledge Mrs. Ilhaam Haniffa for conducting the language editing.

A. Pubudu De Silva, S.H. Padmal De Silva and Isurujith K. Liyanage were supported by the ASCEND Program (https://mspgh.unimelb.edu.au/researchgroups/centre-for-health-equity/non-communicable-disease-unit/ascendresearch-network-program) funded by the Fogarty International Centre, National Institutes of Health, under Award Number: D43TW008332. The contents of this publication is solely the responsibility of the authors and does not necessarily represent the official views of the National Institutes of Health or the ASCEND Program.
}

\section{Funding}

The study was partially funded by the National Health Research Council of Ministry of Health, Sri Lanka.

\section{Availability of data and materials}

The datasets used and/or analyzed during the current study are available from the corresponding author on reasonable request.

\section{Authors' contributions}

APDS gave the original idea, developed the methodology, conducted the training and validation of data collection, data analysis and writing of the manuscript. SHPDS and IKL developed the methodology, supervised data collection, conducted analysis and writing the manuscript. $\mathrm{RH}$ developed the methodology, data analysis and writing of the manuscript. SJ and LCR also gave the original idea, developed the methodology, data analysis and writing of the manuscript. PK, CNW and SW provided valuable assistance to develop the methodology, data analysis and writing of the manuscript. All authors read and approved the final manuscript.

Ethics approval and consent to participate

Ethics approval was obtained from the Ethics Review Committee of Faculty of Medicine, University of Colombo (Reference Number: EC/08/119). Written informed consent was obtained from all study participants.

\section{Competing interests}

The authors declare that they have no competing interests.

\section{Publisher's Note}

Springer Nature remains neutral with regard to jurisdictional claims in published maps and institutional affiliations.

\section{Author details}

${ }^{1}$ Department of Community Medicine, Faculty of Medicine, University of Colombo, Colombo, Sri Lanka. ${ }^{2}$ Centre for Tropical Medicine, University of Oxford, Oxford, UK. ${ }^{3}$ Department of Para Clinical Sciences, Faculty of Medicine, General Sir John Kotelawala University, Colombo, Sri Lanka. ${ }^{4}$ Department of Clinical Medicine, Faculty of Medicine, University of Colombo, Colombo, Sri Lanka. ${ }^{5}$ Department of Obstetrics \& Gynaecology, Faculty of Medicine, University of Colombo, Colombo, Sri Lanka.

Received: 25 July 2017 Accepted: 10 April 2018

Published online: 17 April 2018

\section{References}

1. Wild S, Roglic G, Green A, Sicree R, King H. Global prevalence of diabetes: estimates for the year 2000 and projections for 2030. Diabetes Care. 2004; 27:1047-53

2. Roglic G, Unwin N, Bennett PH, Mathers C, Tuomilehto J, Nag S, et al. The burden of mortality attributable to diabetes: realistic estimates for the year 2000. Diabetes Care. 2005;28:2130-5.

3. Garcia MJ, McNamara PM, Gordon T, Kannell WB. Morbidity and mortality in diabetics in the Framingham population: sixteen year follow-up study. Diabetes. 1974;23:105-11.

4. Brun E, Nelson RG, Bennett PH, Imperatore G, Zoppini G, Verlato G, et al. Diabetes duration and cause-specific mortality in the Verona diabetes study. Diabetes Care. 2000;23:1119-23.

5. Loukine L, Waters C, Choi BCK, Ellison J. Impact of diabetes mellitus on life expectancy and health-adjusted life expectancy in Canada. Popul Health Metr. 2012;10:7.

6. Franco OH, Steyerberg EW, Hu FB, Mackenbach J, Nusselder W. Associations of diabetes mellitus with total life expectancy and life expectancy with and without cardiovascular disease. Arch Intern Med. 2007;167:1145-51.

7. Dall TM, Zhang Y, Chen YJ, Quick WW, Yang WG, Fogli J. The economic burden of diabetes. Health Aff (Millwood). 2010;29:297-303.

8. American Diabetes Association. Economic costs of diabetes in the U.S. in 2012. Diabetes Care. 2013;36:1033-46.

9. Kirigia JM, Sambo HB, Sambo LG, Barry SP. Economic burden of diabetes mellitus in the WHO African region. BMC Int Health Hum Rights. 2009;9:6.

10. Dagogo-Jack S. Primary prevention of type-2 diabetes in developing countries. J Natl Med Assoc. 2006:98:415-9.

11. Rawal LB, Tapp RJ, Williams ED, Chan C, Yasin S, Oldenburg B. Prevention of type 2 diabetes and its complications in developing countries: a review. Int J Behav Med. 2012;19:121-33.

12. Marmot M, Wilkinson RG. Social determinants of health 2nd ed Oxford: Oxford University Press; 2006. 
13. Stringhini S, Tabak AG, Akbaraly TH, Sabia S, Shipley MJ, Marmot MG, et al. Contribution of modifiable risk factors to social inequalities in type 2 diabetes: prospective Whitehall II cohort study. BMJ. 2012;345:e5452.

14. Koskinen SVP, Martelin TP, Valkonen T. Socioeconomic differences in mortality among diabetic people in Finland: five year follow up. BMJ. 1996;313:975-8.

15. Chaturvedi N, Jarrett J, Shipley M, Fuller JH. Socioeconomic gradient in morbidity and mortality in people with diabetes: cohort study findings from the Whitehall study and the WHO multinational study of vascular disease in diabetes. BMJ. 1998;316:100-4.

16. Espelt A, Borrell C, Roskam AJ, Rodriguez-Sanz M, Stirbu I, Dalmau-Bueno A, et al. Socioeconomic inequalities in diabetes mellitus across Europe at the beginning of the 21st century. Diabetologia. 2008;51:1971-9.

17. Bachmann MO, Eachus J, Hopper CD, Davey Smith G, Propper C, Pearcon NJ, et al. Socio-economic inequalities in diabetes complications, control, attitudes and health service use: a cross-sectional study. Diabet Med. 2003;20:921-9.

18. Hsu CC, Lee CH, Wahlgvist ML, Huang HL, Chang HY, Chen L, et al. Poverty increases type 2 diabetes incidence and inequality of care despite universal health coverage. Diabetes Care. 2012;35:2286-92.

19. Gulliford MC, Mahabir D. Social inequalities in morbidity from diabetes mellitus in public primary care clinics in Trinidad and Tobago. Soc Sci Med. 1998:46:137-44.

20. Ramachandran A, Snehalatha C, Baskar ADS, Mary S, Kumar CKS, Selvam S, et al. Temporal changes in prevalence of diabetes and impaired glucose tolerance associated with lifestyle transition occurring in the rural population in India. Diabetologia. 2004;47:860-5.

21. Ramachandran A, Ma RCW, Snehalatha C. Diabetes in Asia. Lancet. 2010;375:408-18.

22. Shera AS, Jawad F, Maqsood A. Prevalence of diabetes in Pakistan. Diabetes Res Clin Pract. 2007;76:219-22.

23. Ono K, Limbu YR, Rai SK, Kurokawa M, Yanagida J, Rai G, et al. The prevalence of type 2 diabetes mellitus and impaired fasting glucose in semi-urban population of Nepal. Nepal Medical College Journal. 2007:9:154-6.

24. Sayeed MA, Mahtab H, Khanam PA, Latif ZA, Banu A, Khan AK. Prevalence of diabetes and impaired fasting glucose in urban population of Bangladesh. Bangladesh Med Res Counc Bull. 2007;33:1-12.

25. Bhowmik B, Afsana F, Diep LM, Munir SB, Wright E, Mahmood S, et al. Increasing prevalence of type 2 diabetes in a rural Bangladeshi population: a population based study for 10 years. Diabetes Metab J. 2013;37:46-53.

26. Illangasekara U, Nugegoda DB, Perera LS. Prevalence of diabetes mellitus and impaired glucose tolerance in a rural Sri Lankan community. CMJ. 1993:38:123-6.

27. Illangasekera U, Tennekon S. Increasing prevelance of diabetes mellitus in rural Sri Lnakan community. Journal of the Ceylon College of Physicians. 2002;33:54-5.

28. Mohideen MR, Weerarathna TP. High prevalence of diabetes mellitus in an urban locality in Galle. Galle Medical Journal. 1996;1:44-5.

29. Wijewardena K, Mohideen MR, Mendis S, Fernando DS, Kulathilaka T, Weerasekara D, et al. Prevlance of hypertension, diabetes and obesity: baseline findings of a population based survey in four provinces in $\mathrm{Sr}$ Lanka. CMJ. 2005:50:62-70.

30. Katulanda P, Constantine GR, Mahesh JG, Sheriff R, Seneviratne RDA, Wijeratne $\mathrm{S}$, et al. Prevalence and projections of diabetes and pre-diabetes in adults in Sri Lanka-Sri Lanka diabetes, cardiovascular study (SLDCS). Diabet Med. 2008:25:1062-9.

31. Katulanda P, Sheriff MHR, Matthews DR. The diabetes epidemic in Sri Lanka - a growing problem. CMJ. 2006:51:26-8.

32. Department of Census and Statistics. Sri Lanka census of population and housing 2011. Colombo: Department of census and Statistics; 2013.

33. De Silva AP, De Silva SHP, Liyanage IK, Rajapakse LC, Jayasinghe KSA, Katulanda $\mathrm{P}$, et al. Social, cultural and economical determinants of diabetes mellitus in Kalutara district, Sri Lanka: a cross sectional descriptive study. Int J Equity Health. 2012;11:76.

34. De Silva AP, De Silva SHP, Haniffa R, Liyanage IK, Jayasinghe KSA, Katulanda P, et al. A cross sectional survey on social, cultural and economic determinants of obesity in a low middle income setting. Int J Equity Health. 2015;14:6.

35. American Diabetic Association. Screening for diabetes. Diabetes Care. 2002;25:S21-4

36. WHO Expert Consultation. Appropriate body-mass index for Asian populations and its implications for policy and intervention strategies. Lancet. 2004;363:157-63.

37. Misra A, Vikram NK, Gupta R, Pandey RM, Wasir JS, Gupta VP. Waist circumference cutoff points and action levels for Asian Indians for identification of abdominal obesity. Int J Obes. 2006;30:106-11.
38. The International Obesity Task Force. The Asia-Pacific perspective: redefining obesity and its treatment. Sydney: Health Communications Australia; 2000.

39. Arambepola C. Abdominal obesity and its association with selected risk factors of coronary heart disease in an adult population in the district of Colombo. Colombo: Postgraduate Institute of Medicine; 2004.

40. De Silva AP. Social determinants of diabetes mellitus in Kalutara District. Colombo: Postgraduate Institute of Medicine; 2010.

41. Satharasinghe A. Census department classifies GN divisions by poverty. Colombo: Department of Census and Statistics; 2008.

42. Wagstaff A, Paci P, Van Doorslaer E. On the measurement of inequalities in health. Soc Sci Med. 1991:33:545-57.

43. Anton E, Kunst AE, Mackenbach JP. Measuring socioeconomic inequalities in health. World Health Organization Regional Office for Europe: Copenhagen; 1999.

44. Schneider MC, Castillo-Salgado C, Bacallao J, Loyola E, Mujica OJ, Vidaurre $M$, et al. Methods for measuring health inequalities (part II). Epidemiol Bull. 2005;26:5-10.

45. Regidor E. Measures of health inequalities: part 2. J Epidemiol Community Health. 2004:58:900-3

46. West KM. Epidemiology of diabetes and its vascular lesions. New York: Elsevier; 1978

47. Mackenbach JP, Stirbu I, Roskam AR, Schaap MM, Menvielle G, Leinsalu M, et al. Socioeconomic inequalities in health in 22 European countries. N Engl J Med. 2008;358:2468-81

48. Espelt A, Kumst AE, Palencia L, Gnavi R, Borrell C. Twenty years of socio-economic inequalities in type 2 diabetes mellitus prevalence in Spain, 1987-2006. Eur J Pub Health. 2011;22:765-71.

49. Espelt A, Borrell C, Palencia L, Goday A, Spadea T, Gnavi R, et al. Socioeconomic inequalities in the incidence and prevalence of type 2 diabetes mellitus in Europe. Gac Sanit. 2013;27:494-501.

50. Hosseinpoor A, Bergen N, Kunst A, Harper S, Guthold R, Rekve D, et al. Socioeconomic inequalities in risk factors for non communicable diseases in low-income and middle-income countries: results from the world health survey. BMC Public Health. 2012:12:912.

51. Sharkey JR, Horel S. Neighborhood socioeconomic deprivation and minority composition are associated with better potential spatial access to the groundtruthed food environment in a large rural area. J Nutr. 2008;138:620-7.

52. Ricci-Cabello I, Ruiz-Perez I, de Labry-lima AO, Marquez-Cakderon S. Do social inequalities exist in terms of the prevention, diagnosis, treatment, control and monitoring of diabetes? A systematic review. Health and Social Care in the Community. 2010;18:572-87.

53. Blakely T, Hales S, Kieft C, Wilson N, Woodward A. The global distribution of risk factors by poverty level. Bull World Health Organ. 2005;83:118-26.

54. Imkampe AK, Gulliford MC. Increasing socio-economic inequality in type 2 diabetes prevalence-repeated cross-sectional surveys in England 1994-2006. Eur J Pub Health. 2011;21:484-90

55. Champernowne DG. A comparison of measures of inequality of income distribution. Econ J. 1974;84:787-816.

56. Portnov BA, Felsenstein D. On the suitability of income inequality measures for regional analysis: some evidence from simulation aqnalysis and bootstrapping test. Socio-Economi Planning Sciences. 2010:44:212-9.

\section{Ready to submit your research? Choose BMC and benefit from:}

- fast, convenient online submission

- thorough peer review by experienced researchers in your field

- rapid publication on acceptance

- support for research data, including large and complex data types

- gold Open Access which fosters wider collaboration and increased citations

- maximum visibility for your research: over $100 \mathrm{M}$ website views per year

At BMC, research is always in progress.

Learn more biomedcentral.com/submissions 